\title{
Visceral larva migrans caused by Trichuris vulpis
}

\author{
TAKASHI SAKANO, KAZUKO HAMAMOTO, YOHNOSUKE KOBAYASHI, \\ YASUKAZU SAKATA, MORIYASU TSUJI, AND TOMOFUSA USUI \\ Department of Paediatrics and Parasitology, Hiroshima University, School of Medicine, Japan
}

SUMMARY Two brothers with visceral larva migrans caused by Trichuris vulpis were diagnosed after they had been investigated for an eosinophilia. Both patients were almost asymptomatic. The diagnosis of visceral larva migrans was based on the results of immunoelectrophoretic studies and no liver biopsy was performed. After administration of thiabendazole, the number of eosinophils and serum total IgE levels gradually decreased, and the patients have remained well.

The term visceral larva migrans (VLM) was first introduced by Beaver et al. ${ }^{1}$ to describe a syndrome in young children characterised by chronic extreme eosinophilia, hepatomegaly, and pulmonary symptoms. Causative parasites most often encountered are Toxocara canis and Toxocara cati. ${ }^{2-3}$ A hog ascaris, Ascaris suum, may also be an aetiological agent. ${ }^{4-5}$ Until now there have been no reports of VLM due to Trichuris vulpis infestation, and two such cases are now reported.

\section{Immunological methods}

Serum antibodies against helminth antigens were detected by Ouchterlony's method and immunoelectrophoresis, using extracts of various helminths as antigens. The extracts were obtained by repeated freezing and thawing of the parasites, after grinding down in $0.1 \%$ sodium chloride solution. After centrifugation, the supernatants were dialysed and lyophilised. These antigens were dissolved in veronal-buffer before use.

Details of immunoelectrophoresis have been described.$^{6}$ Briefly, antigen was first developed by immunoelectrophoresis in agar gel. At the end of the separation, the serum was placed in a trough cut parallel to the path of electrophoretic migration. After incubation at $4^{\circ} \mathrm{C}$, the slide was washed with saline containing veronal-buffer for 3 days and stained with amido black 10B. The arcs of precipitate were examined.

Case 1. A 5-year-old boy was referred to Hiroshima University Hospital for further evaluation of a pronounced eosinophilia. His family had obtained a 10-month-old dog 4 months before he was admitted to hospital. He had been the product of a normal pregnancy and delivery. He started to have occasional asthmatic attacks at $2 \frac{1}{2}$ years, but these had stopped by the age of 4 . His father is currently in good health but he, too, had suffered from bronchial asthma in childhood.

A complaint of fatigue brought him to medical attention at the age of 4 years and 10 months, when an eosinophilia of $16 \%, 1.6 \times 10^{9} / 1$ was first noticed. $\mathrm{He}$ had no other complaints.

On examination, the liver edge was $4 \mathrm{~cm}$ below the costal margin, soft and nontender. Optic fundi were normal. Blood count showed a pronounced eosinophilia of $59 \%, 12.6 \times 10^{9} / 1$, while other haematological values including platelets, reticulocytes, serum iron, and total iron binding capacity were normal. Bone marrow showed a hyperplasia of the eosinophilic series. Serum total protein $7.5 \mathrm{~g} / 100 \mathrm{ml}$, albumin/globulin ratio 1.5 , glutamic-oxalacetic transaminase $26 \mathrm{U} / 1$, glutamic-pyruvic transaminase $14 \mathrm{U} / 1$, and lactic dehydrogenase 491 units. Although the levels of serum IgG, IgA, and IgM were normal, IgE was greatly increased $(6000 \mathrm{U} / \mathrm{ml}$; normal $<500 \mathrm{U} / \mathrm{ml}$ ). Isohaemagglutinins (anti-A) were positive at $1: 512$. Skin tests for house dust, wool, ragweed pollen, and 'tatami' (Japanese floor mats made from Juncus effusus var. decipiens) were positive. Occult blood test in stools was negative.

Repeated stool examinations showed no ova or parasites. However, when the patient's serum was tested in Ouchterlony gel diffusion against various parasite extracts, antibodies against Toxocara canis, Ascaris suum, and Parascaris equorum antigens were detected (Fig. 1). Because of their high antigenicity, cross-reactions between these antigens and antibodies against other kinds of nematode are generally observed. It was now suggested that the patient had contracted a nematode infestation. Faecal specimens 

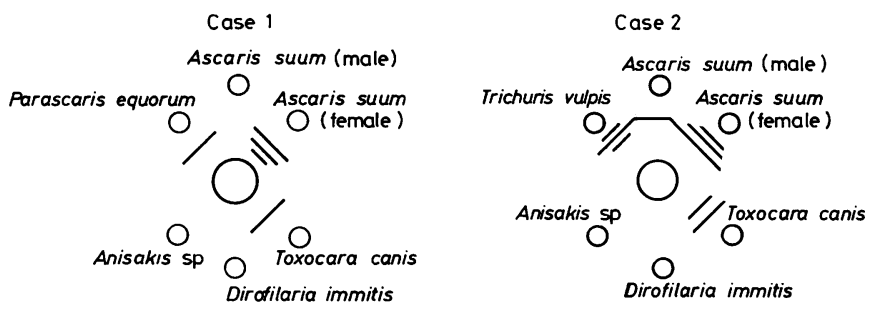

Fig. 1 (Case 1) Ouchterlony gel diffusion: central well was filled by patient's serum.

from the dog showed numerous ova of Trichuris vulpis. Many ova of this parasite were also found in the house dust. The results of immunoelectrophoresis of Trichuris vulpis and Toxocara canis antigens are shown in Fig. 2. Four arcs of precipitate were observed between Trichuris vulpis antigen and the patient's serum. Sera from other patients with

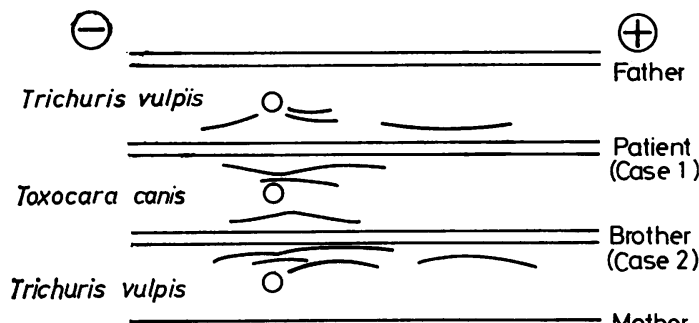

Fig. 2 Immunoelectrophoretic studies of patients and parents.
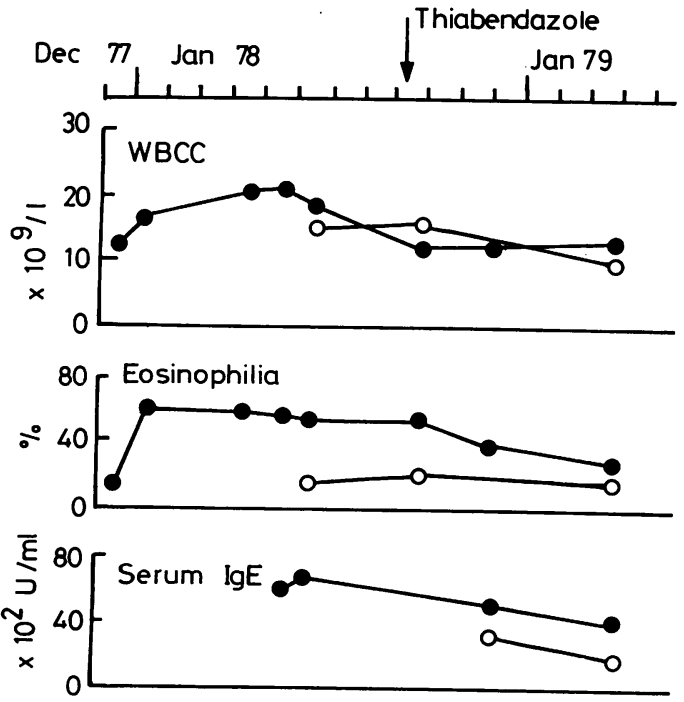

Fig. 3 Temporal changes of peripheral leucocyte count, eosinophilia, and serum IgE levels in Case 1 (closed circles) and Case 2 (open circles).
Toxocara canis or Toxocara cati infestation caused only one or two bands (data not shown), indicating that Trichuris vulpis antigen is different from Toxocara canis or Toxocara cati antigen. The results indicated that our patient had contracted Trichuris vulpis infestation.

Two arcs of precipitate against Toxocara canis antigen were also detected, but these are not specific bands of Toxocara canis antigen. ${ }^{6}$

At age 5 years and 7 months, our patient was given thiabendazole ( $25 \mathrm{mg} / \mathrm{kg}$ per day) for two days. The number of eosinophils in the blood gradually decreased (Fig. 3) and he became well.

Case 2. This 31-month-old boy is the younger brother of Case 1. During investigation of the family an eosinophilia of $15 \%, 1.7 \times 10^{9} / 1$ was found. He had no signs or symptoms suggesting VLM, and physical examination was negative except for some eczema. Complete blood count was normal except for the mild eosinophilia. Serum IgE was increased (3680 $\mathrm{U} / \mathrm{ml}$ ).

Stool examination showed no ova or parasites. Antinematode antibodies were also detected, and immunoelectrophoresis showed four arcs of precipitate against Trichuris vulpis antigen (Fig. 2).

After administration of thiabendazole, the level of serum IgE gradually decreased.

\section{Discussion}

The VLM syndrome, occurring in young children, is characterised by chronic eosinophilia and hepatomegaly, but sometimes lungs, eyes, central nervous system, heart, or other organs can be affected as a consequence of local larval migration. ${ }^{2}$ 7-8 Clinical symptoms are dependent on the severity of the infestation and the extent of tissue involvement. Smith and Beaver ${ }^{9}$ demonstrated that patients who had been given a small number of embryonated ova of Toxocara canis remained clinically asymptomatic despite mild eosinophilia. Both our patients were asymptomatic except that Case 1 tired easily.

Because of the absence of ova in the stools, Snyder ${ }^{7}$ insisted that the conclusive proof of 
diagnosis in suspected cases required liver biopsy and that such biopsy was justifiable in any patient with hepatomegaly and eosinophilia. However, although identification of parasites in the tissues of the host is the final proof of the infestation, their absence does not exclude VLM. This is especially so if the invading parasites are scanty. Under these circumstances, immunological studies are of great value in diagnosis. ${ }^{10}$

In relation to human infestation with Trichuris vulpis, a 4-year-old boy was reported by Hall and Sonnenberg.11 Stools from this patient contained the trichurid ova and a portion of an adult female trichuris was also recovered. Thus, this patient seemed to have suffered from intestinal infestation. Our patients were different from Hall's case, hecause they contracted VLM.

There is no effective specific treatment for VLM as yet. Thiabendazole, a broad-spectrum antihelminthic agent, seems to be effective, because after treatment with this agent the number of arcs of precipitate and eosinophils in peripheral blood decreased, although not to a normal value. Although the possibility of incomplete removal of the parasites cannot be excluded, the remaining eosinophilia may be due to the allergic character of these patients.

\section{Addendum}

Since this article was submitted for publication, an immunoelectrophoretic study at age 6 6 years showed that antinematode antibodies had disappeared from the serum of Case 1.

This work was supported in part by a Grant-in-Aid from the Japan Medical Research Foundation.

\section{References}

1 Beaver P C, Snyder C H, Carrera G M, Dent J H, Lafferty J W. Chronic eosinophilia due to visceral larva migrans. Report of three cases. Pediatrics 1952; 9: 7-19.

2 Mok C H. Visceral larva migrans: a discussion based on review of the literature. Clin Pediatr (Phila) 1968; 7: 565-73.

3 Zinkham W H. Visceral larva migrans: a review and reassessment indicating two forms of clinical expression: visceral and ocular. Am J Dis Child 1978; 132: 627-33.

- Phills J A, Harrold A J, Whiteman G V, Perelmutter L. Pulmonary infilirates, asthma, and eosinophilia due to Ascaris summ infestation in man. N Engl J Med 1972; 286: 965-70.

5 Patterson R, Roberts M, Hart R J, Huntley C C. Evaluation of visceral larva migrans by radioimmunoassay systems. Pediatrics 1975; 56: 417-20.

- Tsuji M. Comparative studies on the antigenic structure of several helminths by immunoelectrophoresis. Jpn $J$ Parasitol 1975; 24: 227-36.

7 Snyder C H. Visceral larva migrans. Ten years' experience. Pediatrics 1961; 28: 85-91.

- Huntley C C, Costas M C, Lyerly A. Visceral larva migrans syndrome: clinical characteristics and immunologic studies in 51 patients. Pediatrics 1965; 36: 523-36.

- Smith M H D, Beaver P C. Persistence and distribution of Toxocara larvae in the tissues of children and mice. Pediatrics 1953; 12 : 491-7.

10 Thomas V, Ogunba E O, Fabiyi A. Review article: the application and limitations of immunodiagnostic techniques in parasitic infections. Afr J Med Med Sci 1978; 7: 107-12.

11 Hall J W, Sonnenberg B. An apparent case of human infection with the whipworm of dogs, Trichuris vulpis. $J$ Parasitol 1956; 42: 197-9.

Correspondence to $\mathrm{Dr} \mathrm{T}$ Sakano, Department of Paediatrics, Hiroshima University, School of Medicine, Hiroshima, Kasumi-Cho, Japan.

Received 26 July 1979 